\title{
Synthesis and evaluation of $\mathrm{pH}-$ sensitive glycopolymers for oral drug delivery systems
}

\author{
Mehrdad Mahkam ${ }^{1 *}$, Reihaneh Mohammadi ${ }^{1}$, Seyed Omid Ranaei Siadat ${ }^{2}$, Seyed \\ Ehsan Ranaei-siadat ${ }^{3}$ \\ ${ }^{1}$ Chemistry Department, Azarbaijan University of Tarbiat Moallem. Tabriz, Iran. \\ Email: mahkam@azaruniv.edu \\ ${ }^{2}$ Department of Biology, Faculty of Science, Shahed University, Tehran, Iran \\ ${ }^{3}$ Department of Biology, Faculty of Science, Ferdowsi University, Meshhad, Iran \\ and \\ New Ideas Research Group
}

(Received: November 16, 2005; Published: April 19, 2006)

\begin{abstract}
Sucrose esters (SE) are surfactants with potential pharmaceutical applications because of their low toxicity, biocompatibility, and excellent biodegradability. Biodegradable and biocompatible copolymeric hydrogels based on glucose-6-acrylate-1, 2, 3, 4-tetraacetate (GATA) and methacrylic acid (MAA) were designed and synthesized. Because of the growing importance of sugar-based hydrogels as drug delivery systems, these new $\mathrm{pH}$-responsive glucose-containing copolymeric hydrogels were investigated for oral drug delivery. The GATA monomer was synthesized and characterized. The copolymeric hydrogel was synthesized by free-radical polymerization. Azobisisobutyronitrile (AIBN) was the free-radical initiator employed and Cubane-1, 4-dicarboxylic acid (CDA) linked to two 2-hydroxyethyl methacrylate (HEMA) group was the crosslinking agent (CA) used for hydrogel preparations. The hydrogels were characterized by differential scanning calorimetry and FT-IR. Equilibrium swelling studies were carried out in enzyme-free simulated gastric and intestinal fluids (SGF and SIF, respectively). A model drug, olsalazine [3, 3-azobis (6-hydroxy benzoic acid)] (OSZ) an azo derivative of 5-aminosalicylic acid (5-ASA), was entrapped in these gels and the in vitro release profiles were established separately in both enzyme-free SGF and SIF. The drug release was found to be faster in SIF. The drug-release profiles indicated that amount of drug release depends on their degree of swelling and crosslinking.

Key words: hydrogel, glucose acrylate, $\mathrm{pH}$-sensitive, oral drug delivery, 5-ASA.
\end{abstract}

\section{Introduction}

Recent years have witnessed significant advances in controlled drug delivery using polymeric materials. Polymeric hydrogels are gaining more attention as drug delivery systems, especially for the controlled release of pharmaceutically active peptides and proteins [1, 2]. Hydrogels have been widely used in many biomedical applications including contact lenses, wound dressings, artificial organs and delivery carriers for bioactive agents because of their high degree of biocompatibility $[3,4]$. High water content and low interfacial tensions with the surrounding biological environment impart biocompatibility to the hydrogels [5]. Stimuli responsive polymers have the possibility to achieve a specific drug release in response to internal or external stimuli [6]. Stimuli 
such as changes in $\mathrm{pH}$, temperature and glucose concentrations help stimuliresponsive polymers to achieve a desired function [7]. Although oral delivery has become a widely accepted route of administration of therapeutic drugs, the gastrointestinal tract presents several formidable barriers against drug delivery. Colonic drug delivery has gained increased importance not just for the delivery of the drugs for the treatment of local diseases associated with the colon but also for its potential for the delivery of proteins and therapeutic peptides. To achieve successful colonic delivery, a drug needs to be protected from absorption in the environment of the upper gastrointestinal tract (GIT) and then be abruptly released into the proximal colon, which is considered the optimum site for colon-targeted delivery of drugs. Targeting of colon is naturally of value for the topical treatment of diseases of colon such as Chron's diseases, ulcerative colitis, colorectal cancer and amebiasis. The various strategies for targeting orally administered drugs to the colon include covalent linkage of a drug with a carrier, coating with $\mathrm{pH}$-sensitive polymers, formulation of time released systems, exploitation of carriers that are degraded specifically by colonic bacteria, bioadhesive systems and osmotic controlled drug delivery systems [8, 9]. Biologically, adhesive delivery systems offer important advantages [10, 11]. The bioadhesion is defined as the ability of a material to adhere to a biological tissue for an extended period of time. Bioadhesive potential of polymers is sufficient to make it suitable for prolonged contact with the intestinal epithelium for extended periods of time and actually penetrate it through and between the cells. Hydrophilic polymers and hydrogels containing carboxyl groups have displayed bioadhesive properties [12, 13]. $\mathrm{pH}$-sensitive hydrogels are not only bioadhesive, but also swell in response to a $\mathrm{pH}$ change. These polymers are able to protect drugs from the acidic $\mathrm{pH}$ of the stomach, and release it in the more basic $\mathrm{pH}$ of the intestine. These materials also appear to temporarily open connections between intestinal cells, allowing the drugs to pass through.

Synthetic polymers containing side-chain carbohydrates are considered as high value polymeric materials because of their potential as biocompatible materials with medical applications. These applications are generally based on the fact that cell-cell interactions between oligosaccharides and lipids play an important role in various life processes [14]. For example, Kobayashi et al. have reported the synthesis of polystyrene having pendent lactose residues and its application as substratum for culture of liver cells [15].

Considering the potential advantages offered by sugar-based polymeric systems, we initiated the design and synthesis of new glucose-containing biocompatible and biodegradable polymeric hydrogels for drug delivery tissue engineering applications. The glucose-6-acrylate-1, 2, 3, 4-tetraacetate (GATA) monomer was synthesized by modification of a synthetic route reported earlier [16]. In this article, we report the synthesis and hydrolytic behavior of glycopolymer hydrogels containing [3, 3-azobis (6-hydroxy benzoic acid)] as azo derivatives of 5-aminosalicylic acid (5-ASA). 5aminosalicylic acid (5-ASA) is useful for localized chemotherapy of inflammatory bowl disease (IBD), but this drug is likely to be absorbed or degraded in the stomach and small intestine before reaching the colon sites. The colon is known to be a reductive medium in which azo groups can be cleaved with formation of the corresponding amines. The metabolic reduction of azo compounds is considered as an important detoxification route [17]. Various prodrugs (sulfasalazine, ipsalazine, balsalazine and olsalazine) have been developed that are aimed to deliver 5-amino salicylic acid (5ASA) for localized chemotherapy of IBD [18]. The most interesting prodrug is olsalazine (OSZ), which is a dimer representing two molecules of 5-ASA that are 
linked via an azo bond. When olsalazine reaches the large intestine, it is cleaved releasing two moles of 5-ASA for every mole of olsalazine administered.

The methacryloyloxyethyl esters of Cubane-1, 4-dicarboxylic acid (CDA) were prepared as a crosslinking agent (CA). Free radical cross-linking copolymerization of the resulting monomer (GATA) and methacrylic acid (MAA) in two different molar ratios, with various ratios of CA produced polymer network bonded drugs (PBDs). The equilibrium swelling studies were carried out in enzyme-free samples of SGF and SIF. OSZ was entrapped as the model drug and in vitro release profiles were established separately in enzyme-free simulated gastric and intestinal fluids SGF and SIF, respectively.

\section{Experimental}

\section{Materials}

Cubane-1, 4-Bis (methacryloyloxyethyl) carboxylate (CA) was prepared by the method described in the literature [19]. Triphenylcarbinol and methacrylic acid (MAA) were purchased from Merck Co. The solvents and reagents were obtained from Fluka. The IR spectra were recorded on a Shimadzu FT IR-408 spectrophotometer. The DSC curves were obtained on a TGA/SDTA 851 calorimeter at heating and cooling rates of $10^{\circ} \mathrm{C} / \mathrm{min}$ under $\mathrm{N}_{2}$. The amount of released drug was determined on a Philips PU 8620 UV spectrophotometer at the absorption maximum of the free drug in aqueous alkali $(\lambda \max =245 \mathrm{~nm})$ using a $1 \mathrm{~cm}$ quartz cell. Enzyme-free SGF $(\mathrm{pH} 1)$ or SIF $(\mathrm{pH}$ 7.4) were prepared according to the method described in the US Pharmacopoeia [20]. The HPLC apparatus (Bischoff, Germany) consisted of Bruker LC-21, equipped with a Bruker UV-Vis detector model LC 313 I, Rheodyne loop injector and a C18 reversephase column of Spherisorb-CN (250 × $4.6 \mathrm{~mm}$ id., particle size $5 \mu \mathrm{m})$.

\section{Synthesis of triphenylchloromethane: (TPhCM)}

A mixture of $250 \mathrm{~g}$ of pure triphenylcarbinol and $80 \mathrm{~mL}$ of dry benzene was placed in a 1 liter round-bottomed flask provided with a reflux condenser. The condenser was provided with a calcium chloride tube at the top. The mixture was heated on a steam bath, when it becomes hot; $50 \mathrm{~mL}$ of acetyl chloride is added through the top of the condenser. Heating was continued while the mixture is shaken vigorously. In about 5 minutes all the solid triphenylcarbinol disappeared resulting in a clear solution. In the course of 10 minutes, an additional $100 \mathrm{~mL}$ of acetyl chloride was added in $10 \mathrm{~mL}$ portions. The solution was then refluxed for 30 minutes longer. The solution was cooled by shaking the flask under running water and during this operation $200 \mathrm{~mL}$ of petroleum ether was added through the top of the condenser, and the triphenylchloromethane separated in sugarlike crystals. The mixture was cooled in an ice bath for 1-2 hours, and the product filtered, washed with $150 \mathrm{~mL}$ of petroleum ether and dried in vacuum. The yield was $224 \mathrm{~g} \mathrm{(83 \% )} \mathrm{and} \mathrm{the} \mathrm{TPhCM} \mathrm{melts} \mathrm{at} 111^{\circ}$ C.

\section{Synthesis of 6-trityl- $\beta$-d-glucose-1, 2, 3, 4-tetraacetate: (TGTA)}

A mixture containing $120 \mathrm{~g}(0.67 \mathrm{~mol})$ of anhydrous glucose, $193.2 \mathrm{~g}(0.7 \mathrm{~mol})$ of trityl chloride and $500 \mathrm{~mL}$ of anhydrous pyridine was heated on the steam cone until complete dissolution. Without cooling, $360 \mathrm{~mL}$ of acetic anhydride was added in one 
portion. The reaction mixture was poured slowly into 10 Liter of ice water, to which 500 $\mathrm{mL}$ of acetic acid has been added, after keeping for 12 hours. Vigorous mechanical stirring of the mixture for 2 hours resulted in white granular precipitate which was filtered, washed well with cold water and then air dried. The dried solid was digested with $500 \mathrm{~mL}$ of ether (the $\alpha$-isomer is soluble in ether but the $\beta$-isomer is insoluble). The insoluble portion was dissolved in hot $95 \%$ ethanol (approximately 3 liter) and the solution was decolorized and filtered while it was still hot. The filtrate upon cooling, deposited fine needles of 6 -trityl- $\beta$-d-glucose-1, 2, 3, 4-tetraacetate of sufficient purity for further use. The yield at this point was about $169 \mathrm{~g} \mathrm{(43 \% ).} \mathrm{Recrystallization} \mathrm{from}$ $95 \%$ ethanol gave the pure compound which melts at $166^{\circ} \mathrm{C}$. The yield of purified material was $137 \mathrm{~g}(35 \%)$. In pyridine, $[\alpha]^{19}$ is $+44.8^{\circ}$ and $[\alpha]^{28}+45.3^{\circ}$. IR $(\mathrm{KBr})$ : 3061, 2969, 1740, 1598, 1490, $1219 \mathrm{~cm}^{-1} .{ }^{1} \mathrm{H}-\mathrm{NMR}\left(\mathrm{CDCl}_{3}\right): \delta 2.1$ (d, $\left.12 \mathrm{H},-\mathrm{CH}_{3}\right), 3.8$ $(\mathrm{m}, 1 \mathrm{H}), 4.1(\mathrm{dd}, 1 \mathrm{H}), 4.28(\mathrm{dd}, 1 \mathrm{H}), 5.1\left(\mathrm{~m}, 2 \mathrm{H},-\mathrm{CH}_{2}\right), 5.24(\mathrm{t}, 1 \mathrm{H}), 7.3(\mathrm{~d}, 15 \mathrm{H}, \mathrm{Ph})$.

\section{Synthesis of $\beta$-d-glucose-1, 2, 3, 4-tetraacetate: (GTA)}

A solution of $46 \mathrm{~g}(0.078 \mathrm{~mol})$ of 6 -trityl- $\beta$-d-glucose-1, 2, 3, 4-tetraacetate in $200 \mathrm{~mL}$ of acetic acid was prepared by warming on the steam bath. The solution was then cooled to approximately $10^{\circ} \mathrm{C} .18 \mathrm{~mL}$ of a saturated solution of dry hydrogen bromide in acetic acid was added, and the reaction mixture was shaken for about 45 seconds. The trityl bromide formed during the reaction was removed at once by filtration, and the filtrate poured immediately into 1 liter of cold water. The tetraacetate was extracted with $250 \mathrm{~mL}$ of chloroform. The chloroform extract was washed four times with ice water and dried over anhydrous sodium sulfate. The drying agent was removed and the chloroform was evaporated under reduced pressure at room temperature. The remaining syrup was covered with $100 \mathrm{~mL}$ of anhydrous ether and rubbed with a glass rod and crystallization occurred immediately. The product was removed and purified by dissolving it in the minimum amount of chloroform and adding anhydrous ether until crystallization started. The yield was $15 \mathrm{~g} \mathrm{(55 \% )}$. The purified product melts at $128^{\circ} \mathrm{C}$. In chloroform, $[\alpha]^{20}$ is $+12.1^{\circ}$. IR $(\mathrm{KBr}): 3478,2970,1735,1210 \mathrm{~cm}^{-1} .{ }^{1} \mathrm{H}-\mathrm{NMR}\left(\mathrm{CDCl}_{3}\right)$ : ठ $2.1\left(\mathrm{~d}, 12 \mathrm{H},-\mathrm{CH}_{3}\right), 3.8(\mathrm{~m}, 1 \mathrm{H}), 4.1(\mathrm{dd}, 1 \mathrm{H}), 4.28(\mathrm{dd}, 1 \mathrm{H}), 5.2\left(\mathrm{~m}, 2 \mathrm{H},-\mathrm{CH}_{2}\right), 5.27$ $(\mathrm{t}, 1 \mathrm{H})$.

\section{Synthesis of glucose-6-acrylate-1, 2, 3, 4-tetraacetate: (GATA)}

A mixture of $1.5 \mathrm{~g}(0.004 \mathrm{~mol}) \mathrm{GTA}$ and $1.3 \mathrm{~g}$ triethylamine in $30 \mathrm{~mL}$ dried THF was added with stirring to a solution of $1.17 \mathrm{~g}(0.012 \mathrm{~mol})$ acryloyl chloride in $10 \mathrm{~mL}$ THF under $\mathrm{N}_{2}$ at $-5^{\circ} \mathrm{C}$. The stirring was continued at room temperature for $24 \mathrm{~h}$. The precipitated was filtered, and the filtrate was poured into $50 \mathrm{~mL}$ of cold acetone to precipitate the GATA. The solid product was filtered, washed with cold acetone and dried in vacuum which afforded of GATA as a white solid (Scheme 1). IR (KBr): 2937, 1755, 1618, 1261, $1225 \mathrm{~cm}^{-1} .{ }^{1} \mathrm{H}-\mathrm{NMR}\left(\mathrm{CDCl}_{3}\right): \delta 2.1\left(\mathrm{~d}, 12 \mathrm{H},-\mathrm{CH}_{3}\right), 3.8(\mathrm{~m}, 1 \mathrm{H}), 4.1$ $(\mathrm{dd}, 1 \mathrm{H}), 4.28(\mathrm{dd}, 1 \mathrm{H}), 5.1\left(\mathrm{~m}, 2 \mathrm{H},-\mathrm{CH}_{2}\right), 5.24(\mathrm{t}, 1 \mathrm{H}), 6.2(\mathrm{~m}, 1 \mathrm{H},-\mathrm{C}=\mathrm{CH}), 6.8(\mathrm{~m}, 2 \mathrm{H}$, $\mathrm{CH}_{2}=\mathrm{C}$ ) (Scheme 1) . 

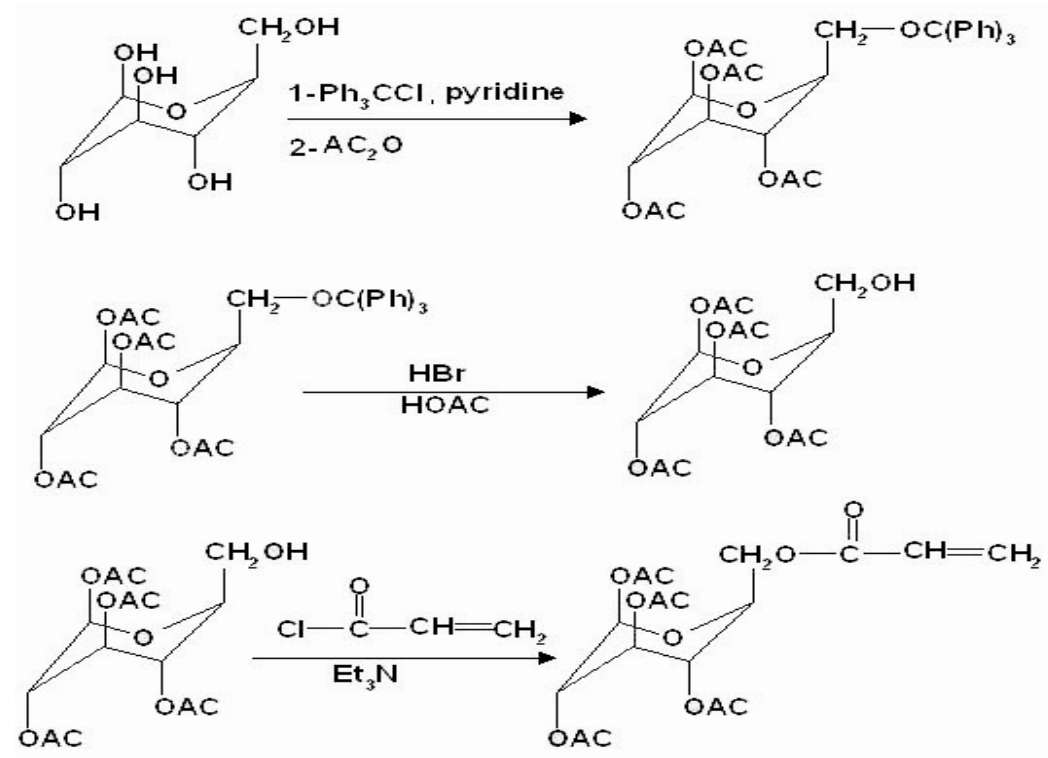

Scheme 1. Preparation of GATA.

\section{Copolymerization: General Procedure}

Specific mol percents of CA (5 and 10\%) with mixture of two different molar ratios $(1: 3,1: 5)$ of GATA and methacrylic acid were polymerized at $60-70^{\circ} \mathrm{C}$ in a thermostatic water bath, using 2, 2'-azobisisobutyronitrile (AIBN) as initiator $([\mathrm{l}]=0.02$ $\mathrm{M})$, and dried dioxane as solvent $([\mathrm{M}]=1 \mathrm{M})$. All experiments were carried out in Pyrex glass ampoules sealed under vacuum. After the specific time (48 h), the precipitated network polymer was collected and dried in vacuum (scheme 2).
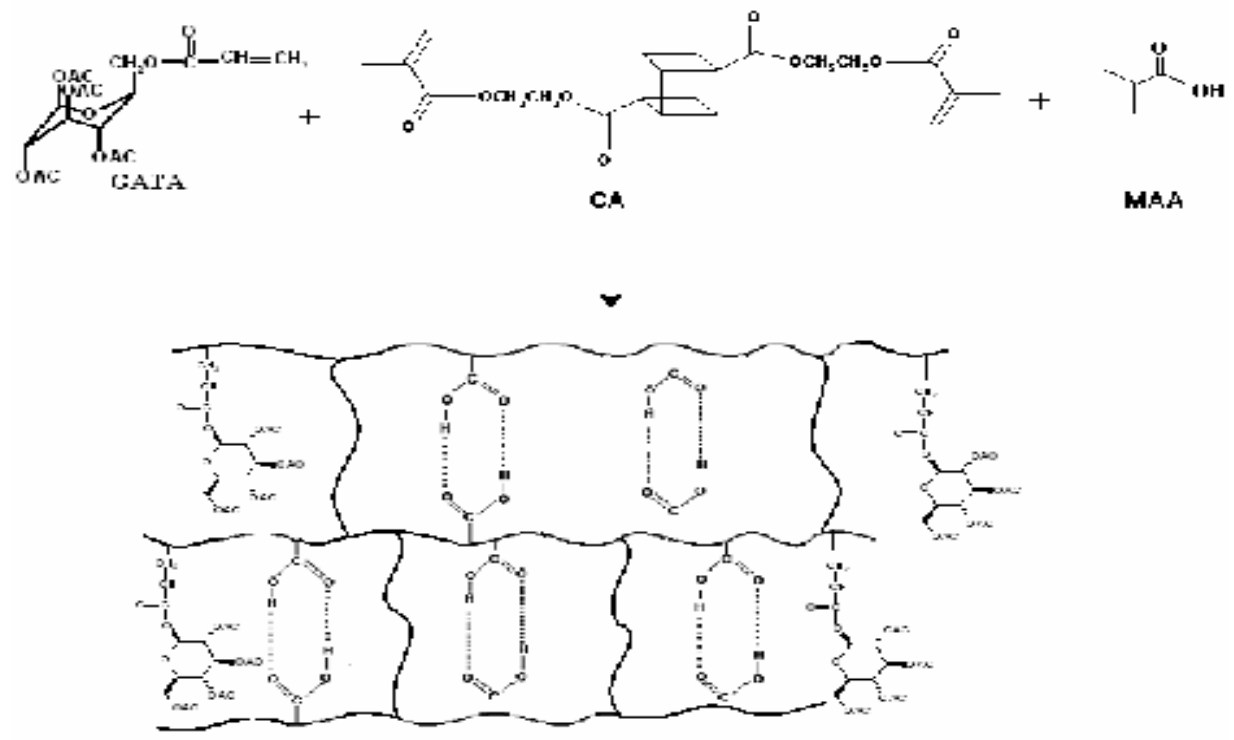

Scheme 2. Preparation of network's glycopolymers. 


\section{Drug loading in hydrogels}

$20 \mathrm{mg}$ of each hydrogel was dispersed with stirring in $5 \mathrm{~mL}$ of solution containing $2 \mathrm{mg}$ of OSZ to suck up the total amount of the drug solution. After approximately $60 \mathrm{~min}$, the completely swollen hydrogels loaded with drug were placed in desiccators and dried under vacuum at room temperature.

\section{Determination of amount of drug entrapped}

The amount of drug entrapped in the hydrogels was determined by an indirect method. After gel preparation, the washings with methanol were collected and tested using UV-Vis spectroscopy. The difference between the amount of drug initially employed and the drug content in the washings was taken as an indication of the amount of drug entrapped. The values of quantification of entrapped drug in the hydrogel based on the total amount are given in Table1.

Tab. 1. DSC data and composition of copolymers.

\begin{tabular}{|c|c|c|c|c|}
\hline Polydrugs & $\begin{array}{c}\frac{\text { Molar composition of }}{\text { monomers in the feed }} \\
\text { GATA and MAA }\end{array}$ & CA (\%) & $\begin{array}{c}\text { Percent of drug-loading } \\
\text { (mg of drug loading) / }(22 \mathrm{mg}) \times 100\end{array}$ & $\mathrm{Tg}\left({ }^{\circ} \mathrm{C}\right)$ \\
\hline PBDs-1 & $1: 3$ & 5 & 9.8 & 190 \\
PBDs-2 & $1: 3$ & 10 & 9.8 & 205 \\
PBDs-3 & $1: 5$ & 10 & 9.8 & 200 \\
PBDs-4 & $1: 5$ & 9.8 & 225 \\
\hline
\end{tabular}

\section{Characterization of hydrolysis product}

Polymer-drug adduct $(90 \mathrm{mg}$ ) was dispersed in $20 \mathrm{~mL}$ of $\mathrm{pH} 8$ buffered solution. The reaction mixture was maintained at $37^{\circ} \mathrm{C}$. After $24 \mathrm{~h}$ the hydrolysis solution was sampled and neutralized with $1 \mathrm{M} \mathrm{HCl}$ and the solvent was evaporated in vacuum. The resulting crude product was treated with $10 \mathrm{~mL}$ of acetone and heated. The suspension was then filtered and the acetone solution was evaporated under reduced pressure. Samples were measured using HPLC-UV. The column used was ODS (C18) and isocratic elution was performed using 50\% methanol and 50\% buffer containing $0.05 \mathrm{M} \mathrm{NH}_{3}$. The flow-rate and injection volume were $1 \mathrm{~mL} / \mathrm{min}$ and $100 \mu \mathrm{L}$, respectively. OSZ was detected at a retention time of $2.8 \mathrm{~min}$.

\section{In vitro release studies}

The copolymers ( $50 \mathrm{mg}$ ) were poured into $3 \mathrm{~mL}$ of aqueous buffer solution (SGF: $\mathrm{pH} 1$ or SIF: $\mathrm{pH}$ 7.4). The mixture was introduced into a cellophane membrane dialysis bag. The bag was closed and transferred to a flask containing $20 \mathrm{~mL}$ of the same solution maintained at $37^{\circ} \mathrm{C}$. The external solution was continuously stirred, and $3 \mathrm{~mL}$ samples were removed at selected intervals. The volume removed was replaced with SGF or SIF. Triplicate samples were used. The sample of hydrolyzate was analyzed by UV spectrophotometer, and the quantity of OSZ as an azo derivative of 5-ASA was determined using a standard calibration curve obtained under the same conditions. 


\section{Measurement of swelling ratio}

The synthesized network polymers swell and become soft in solvents such as $\mathrm{H}_{2} \mathrm{O}$ and most organic solvents without dissolving. To measure the swelling, preweighed dry drug-free hydrogels were immersed in various buffer solutions $(\mathrm{pH} 7.4$ and $\mathrm{pH} 1)$ at $37^{\circ} \mathrm{C}$. After excess water on the surface was removed with the filter paper, the weight of the swollen samples was measured at various time intervals. The procedure was repeated until there was no further weight increase. The degree of swelling was calculated according the relation:

$\mathrm{SW}(\%)=\left[\left(\mathrm{W}_{\mathrm{s}}-\mathrm{W}_{\mathrm{d}}\right) / \mathrm{W}_{\mathrm{d}}\right] \times 100$

where, $W_{s}$ and $W_{d}$ represent the weight of swollen and dry samples, respectively. Time-dependent swelling behavior of cross-linked polymers in $\mathrm{pH} 1$ and $\mathrm{pH} 7.4$ at $37^{\circ}$ $\mathrm{C}$ are plotted in Figure 1.

\section{Results and Discussion}
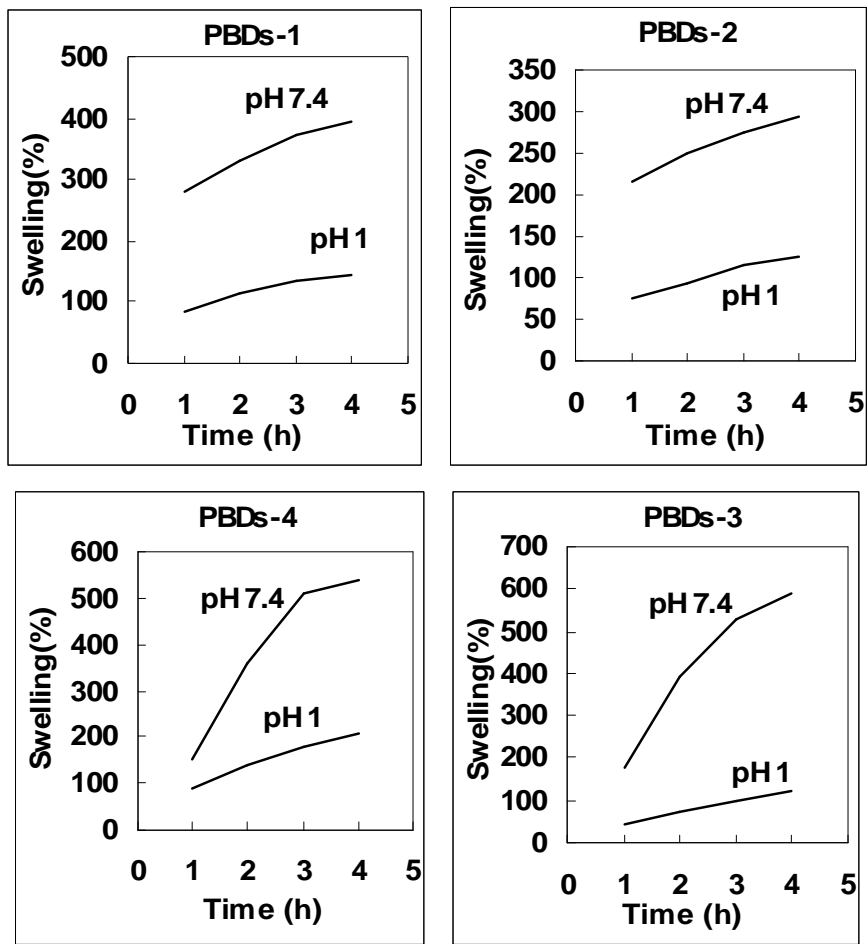

Fig. 1. Time-dependent swelling behavior of cross-linked glycopolymers at $37^{\circ} \mathrm{C}$.

Drug delivery to the colon has implications in a number of therapeutic areas, particularly in the treatment of colonic diseases such as ulcerative colitis and Chron's disease and in the oral delivery of peptides and other drugs degraded in the upper gastrointestinal tracts. Ionic hydrogels, which could be cationic, containing basic functional groups or anionic, containing acidic functional groups, have been reported to be very sensitive to changes in the environmental $\mathrm{pH}$. The swelling properties of the ionic hydrogels are unique due to the ionization of their pendent functional groups. Because hydrophilic polymers and hydrogels containing carboxylic groups have displayed bioadhesive properties, design and synthesis of new biodegradable and 
biocompatible polymeric hydrogel systems based on suger-containing monomers was the primary objective in our study. We were interested in the chemical modification of $\mathrm{pH}$-sensitive hydrogel, especially by glycosidation reactions. Its success promises to attract much attention as a new type of synthetic polymer with pendent sugar residues for producing not only biodegradable but biomedically useful materials. These polymeric hydrogels containing hydrophilic constituents are expected to serve not only as drug delivery matrices for oral drug delivery but also as tissue engineering scaffolds. The bioadhesive character of both the sugar monomer and the methacrylic acid serve the purpose of prolonged attachment to the mucous membrane in the gastrointestinal (Gl) tract for controlled drug delivery. As shown in figure 1, an increase in the content of MAA in the feed monomer mixtures resulted in less swelling in SGF but greater swelling in SIF. This is because the increase of MAA content in the hydrogels provides more hydrogen bonds at low $\mathrm{pH}$ and more electrostatic repulsion at high $\mathrm{pH}$. Based on this rationale, we have synthesized new hydrogels containing different molar ratios of acidic monomers. In the low pH range of the stomach, the gels have a low equilibrium degree of swelling and the drug is protected against digestion by enzymes. The degree of swelling increases as the hydrogel passes down the gastrointestinal tract due to increased $\mathrm{pH}$. In colon, the gels have reached a high degree of swelling that makes the drug being released from the gel.

\section{Thermal Behavior}

The thermal behavior of a polymer is important in relation to its properties for controlling the release rate in order to have a suitable drug dosage form. Differential scanning calorimetry (DSC) and Thermal gravimetry (TGA) for the network polymers were evaluated. The glass transition temperature $(\mathrm{Tg})$ was determined from the DSC thermograms. The values are given in Table1. The higher $\mathrm{Tg}$ values probably related to the introduction of crosslinks, which would decrease the flexibility of the chains and the ability of the chains to undergo segmental motion, which would increase the $\mathrm{Tg}$ values [19]. On the other hand the introduction of a strongly polar carboxylic acid group can increase the $\mathrm{Tg}$ value because of the formation of internal hydrogen bonds between the polymer chains.

\section{Drug Release by Hydrolysis of Polymer Bonded Drugs}

In order to study potential application of PBDs containing azo derivatives of 5aminosalicylic acid as a pharmaceutically active compound, we have studied the drug releases behavior of the polymers under physiological conditions. Although the polymers were not soluble in water, they were dispersed in a buffer solution, and the drug release was evaluated as a heterogeneous system. The percent of released drug from polymeric carriers as a function of time is shown in Figure 2. The concentration of OSZ released at selected time intervals was determined by UV spectrophotometry at $245 \mathrm{~nm}$. The order of release in this series was significantly affected by polymer composition. It appears that the degree of drug release from network polymers depends on the degree of swelling and reticulation. The increase in crosslinking density through addition of crosslinking agents are known to reduce the equilibrium swelling. Reduced swelling is often marked with reduced diffusion coefficient. 

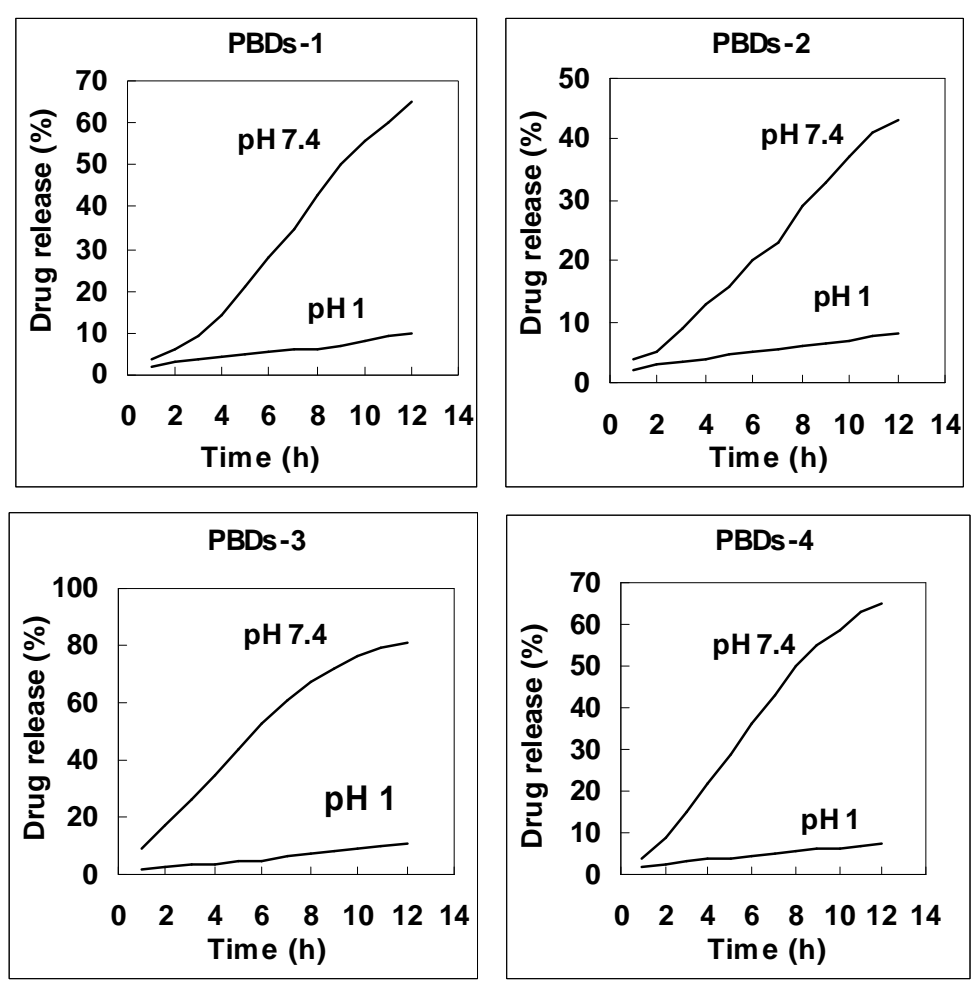

Fig. 2. Release of OSZ from polymeric carriers as a function of time at $37^{\circ} \mathrm{C}$.

On the other hand, a high different hydrolysis rate for polymers at $\mathrm{pH} 1$ and 7.4 can be related to the number of carboxylic acid groups on monomeric units along the polymer chain. At low $\mathrm{pH}$, polymers have a low equilibrium degree of swelling but these increases due to increased $\mathrm{pH}$. At $\mathrm{pH} 7.4$ with complete ionization and increased hydrophilicity of the polymer, swelling of polymer is increased and the drug release rate was increased [21].

\section{Conclusions}

The oral administration of drugs is the most attractive route. However reduced gastrointestinal side effects and degradation of drugs makes the large intestine optimal for drug delivery due to the high residence time and low digestive enzymatic activity. The metabolic reduction of OSZ in colon equipped the anti-inflammatory agent 5-ASA for colon specific drug delivery. The swelling and hydrolytic behavior of the hydrogels was dependent on the content of MAA groups and caused a decrease in gel swelling in SGF or an increase in gel swelling in SIF [22-24]. Methacrylic-type polymeric prodrugs with different contents of MAA and CA were synthesized by free radical cross-linked copolymerization. By regulating the crosslinking percentage of the MAA copolymers, $\mathrm{pH}$-sensitive hydrogels with improved optimal hydrolysis rates were obtained. The drug release of drug-polymer conjugates were carried out at $\mathrm{pH} 1$ and $\mathrm{pH} 7.4$ at $37^{\circ} \mathrm{C}$. The drug-release profiles indicated that the drug entrapped in hydrogels is released faster in SIF than in SGF as a result of the $\mathrm{pH}$ sensitivity. These preliminary investigations also revealed that GATA hydrogels could be applied for the oral drug delivery by virtue of both the bioadhesive and $\mathrm{pH}$-sensitive nature of the glucose-based polymeric systems. This study also envisaged the potential of these matrices for tissue engineering applications. Based on the great difference in 
hydrolysis rates at $\mathrm{pH} 1$ and 7.4, these hydrogels appears to be good candidates for colon-specific drug delivery.

\section{Acknowledgements}

The authors thank the Institute of chemical science and technology-Tehran-Iran (ICST-8I03-2116) for supporting this work.

\section{References}

1. Bell, C. L.; Peppas, N. A.; Biomaterials. 1996, 17, 1203.

2. Wang, C.; Stewart, R. J.; Kopecek, J.; Nature. 1999, 397, 417.

3. Yoshida, R.; Sakai, K.; Okano, T.; Sakurai, Y.; Adv. Drug. Delivery. Rev. 1993, 11, 85.

4. Cheng, J.; Jo, S.; Park, K.; Carbohydr Polym. 1995, 28, 69.

5. Dong, L. C.; Yan, Q.; Haffman, A. S.; J. Controlled Release. 1992, 19, 171.

6. Kost, J.; Pulsed and self-regulated drug delivery, CRC Press: Boca Raton, FL. 1990.

7. Okano, T.; Yui, N.; Yokoyama, M.; Yoshida, R.; Advances in polymeric systems for drug delivery, Gordon \& Breach: New York. 1994.

8. BrØndsted, H.; Kopeček, J.; Hydrogels for site-specific oral delivery, Proc. Int. Symp. Control. Rel. Bioact. Mater. 1990. 17, 128.

9. Joshi, H. N.; Recent advances in drug delivery systems, polymeric prodrugs.; Pharm. Technol. 1988, 12, 112.

10. Davis, S. S.; Illum, L.; Biomaterials. 1988, 9, 111.

11. Frisbie, C. D.; Lawrence, F.; Rozsnyai, A. N.; Wrighton, M. S.; Charles, M. L.; Science. 1994, 265, 2071.

12. Peppas, N. A.; hydrogels in medicine and pharmacy, CRC Press: Boca Raton, FL. 1987.

13. Lenaerts, V.; Couvreur, P.; Grislain, L.; Maincent, P.; Bioadhesive drug delivery systems, CRC Press: Boca Raton, FL. 1990, pp 93-104.

14. Zhou, W. J.; Wilson, M. E.; Kurth, M. J.; Hsieh, Y. L.; Krochta, J. M.; Shoemaker, C. F.; Macromolecules 1997, 30, 7063.

15. Kobayashi, A.; Akaike, T.; Kobayashi, K.; Sumitomo, H.; Makromol Chem Rapid Commun. 1986, 7, 645.

16. Organic Synthesis, Coll. Vol. 22, p. 100.

17. Mahkam, M.; J. Bioact. Comp.Polym. 2004, 19(3) 209-220.

18. Chourasia, M. K.; Jain, S. K.; J. Pharm. Pharma. Sci. 2003, 6(1): 33-66.

19. Mahkam, M.; Sharifi, N.; Entezami, A. A.; J. Bioact. Comp. Polym. 2000, 15, 396404. 
20. US Pharmacopeial Convention, Inc. The United State Pharmacopeia, $24^{\text {th }}$ ed. Rockvile, MD: US Pharmacopeial Convention, Inc.; 1999.

21. Kopeček, J.; Kopečková, P.; BrØndsted, H.; Rathi, R.; Řihoá, B.; Yeh, P. Y.; Ikesue, K.; J. Control. Rel. 1992, 19, 121-130.

22. Ulbrich, K.; Strohalm, J.; Kopeček, J.; polymers containing enzymatically degradable bonds; Biomaterials. 1982, 3, 150-154.

23. Mooter, G. V.; Samyn, C.; Kinglet, R.; J. Pharm. Res. 1994, 11, 12.

24. Mahkam, M.; Doostie, L.; J. Drug Delivery. 2005, 12 (6), 343. 